\title{
Article
}

\section{Carotid Beta Stiffness Association with Thyroid Function}

\author{
Alessandro P. Delitala ${ }^{1,2, *}$, Angelo Scuteri ${ }^{1}$, Edoardo Fiorillo ${ }^{2}$, Valeria Orrù ${ }^{2}$, Edward G. Lakatta ${ }^{3}$, \\ David Schlessinger ${ }^{4}$ and Francesco Cucca ${ }^{2,5}$ \\ 1 Department of Medical, Surgical, and Experimental Sciences, University of Sassari, 07100 Sassari, Italy; \\ ascuteri@uniss.it \\ 2 Istituto di Ricerca Genetica e Biomedica (IRGB), Consiglio Nazionale delle Ricerche, c/o Cittadella \\ Universitaria di Monserrato, 09042 Cagliari, Italy; edoardo.fiorillo@irgb.cnr.it (E.F.); \\ valeria.orru@irgb.cnr.it (V.O.); fcucca@uniss.it (F.C.) \\ 3 Laboratory of Cardiovascular Sciences, National Institute on Aging Intramural Research Program, \\ National Institutes of Health, Baltimore, MD 21224, USA; lakattae@grc.nia.nih.gov \\ 4 National Institute on Aging, NIH, DHHS, Baltimore, MD 21224, USA; SchlessingerD@grc.nia.nih.gov \\ 5 Department of Biomedical Sciences, University of Sassari, 07100 Sassari, Italy \\ * Correspondence: aledelitala@uniss.it; Tel.: +39-079-228-184; Fax: +39-079-228-207
}

Citation: Delitala, A.P.; Scuteri, A.; Fiorillo, E.; Orrù, V.; Lakatta, E.G.; Schlessinger, D.; Cucca, F. Carotid Beta Stiffness Association with Thyroid Function. J. Clin. Med. 2021, 10, 420. https://doi.org/10.3390/ jcm10030420

Academic Editor: Massimo Terzolo Received: 25 December 2020 Accepted: 20 January 2021

Published: 22 January 2021

Publisher's Note: MDPI stays neutral with regard to jurisdictional claims in published maps and institutional affiliations.

Copyright: (C) 2021 by the authors. Licensee MDPI, Basel, Switzerland. This article is an open access article distributed under the terms and conditions of the Creative Commons Attribution (CC BY) license (https:/ / creativecommons.org/licenses/by/ $4.0 /)$.

\begin{abstract}
Background: Thyroid hormone modulation of cardiovascular function has been associated with cardiovascular disease. Recent evidence suggests that free thyroxine (FT4) levels are associated with an increase in systemic arterial stiffness, but little is known about the effects of FT4 at the local level of the common carotid artery. $\beta$-stiffness index is a local elastic parameter usually determined by carotid ultrasound imaging. Methods: We conducted a cross-sectional analysis in the ProgeNIA cohort, including 4846 subjects across a broad age range. For the purpose of this study, we excluded subjects with increased thyrotropin (TSH) levels and those treated with levothyroxine or thyrostatic. We assessed $\beta$ stiffness, strain, wall-lumen ratio, carotid cross-sectional area (CSA), and stress and flow in the right common carotid artery. We tested whether FT4, heart rate, and their interactions were associated with carotid parameters. Results: FT4 was positively and independently associated with $\beta$ stiffness index $(\beta=0.026, p=0.041)$, and had a negative association with strain $(\beta=-0.025, p=0.009)$. After adding heart rate and the interaction between FT4 and heart rate to the model, FT4 was still associated with the $\beta$ stiffness index $(\beta=0.186, p=0.06)$, heart rate was positively associated with the stiffness index $(\beta=0.389, p<0.001)$ as well as their interaction $(\beta=0.271, p=0.007)$. Conclusion: This study suggests that higher FT4 levels increase arterial stiffness at the common carotid level, consistent with a detrimental effect on elastic arteries. The effect of FT4 is likely to be primarily attributable to its effect on heart rate.
\end{abstract}

Keywords: thyroxine; carotid beta stiffness; aging; carotid strain; thyroid hormone; heart rate

\section{Introduction}

Thyroid hormone physiologically regulates different cardiovascular parameters [1]. These effects become more evident during disorders of the thyroid gland. Hypothyroidism usually has a detrimental effect on lipid metabolism [2], with an increase in atherogenic low density lipoprotein cholesterol (LDL) and triglycerides, along with gender and sex hormone effects having been also postulated [2,3]. The role of levo-thyroxine replacement therapy has been clearly demonstrated in overt disease, but its role in subclinical hypothyroidism remains less clear $[4,5]$. In contrast to low thyroid function, hyperthyroidism causes an increase in metabolic rate, and is associated with increased cardiovascular activity [6]. Indeed, increased heart contractility, frequency, and vasodilation are typically noted in hyperthyroid patients [7].

Although changes associated with aging have not yet been adequately characterized, aging is well known to have profound effects on the cardiovascular system. Arterial 
stiffening, beginning early in the life-course [8,9], is a major feature of aging and has been associated with increased cardiovascular (CV) morbidity and disability [10].

Due to its ability to predict early vascular disease, the evaluation of arterial stiffness has been recommended as a diagnostic tool in the most recent guidelines from the European Society of Cardiology (ESC) [11]. Different techniques have been developed to measure arterial stiffness non-invasively, and carotid-femoral pulse wave velocity (PWV) is acknowledged as the gold standard to assess arterial stiffness [12]. The $\beta$ stiffness index reflects age-related stiffening of the carotid artery [13]. The resulting impairment causes a loss of the ability to buffer a pulsatile flow and the pressure generated during systole, thus transmitting excessive flow pulsatility and pressure into the brain microcirculation [14,15].

Carotid stiffness has been associated with the incident of stroke [16], incident of CV events [17], and a reduction in renal function [18]. Compared to carotid-femoral PWV, exploring systemic large artery stiffening of the carotid can provide more information on local alterations in the elastic properties of the arterial wall biomaterial [19], on functional arterial stiffening secondary to endothelial dysfunction [20], and local alterations in pulsatility [21], with consequent carotid remodelling [22].

The role of thyroid hormone on arterial stiffening is not clear. Indeed, previous studies reported a negative effect of hypothyroidism on PWV [23], which improved after treatment with levothyroxine [24]. However, a previous study by our group demonstrated a positive association between free thyroxine (FT4) and increased carotid-femoral PWV [25]. In this study we extend the analysis, testing the association between thyroid hormones and the $\beta$ stiffness index at the common carotid level.

\section{Materials and Methods}

The ProgeNIA study investigates hundreds of genotypic and phenotypic aging-related traits in a longitudinal survey [26,27]. From the initial sample of 6148 individuals, subjects who reported taking thyroid medications (thyroid hormone replacement or thyrostatics) or drugs that alter thyroid function tests (amiodarone, lithium, and corticosteroids), and those with subclinical or overt hypothyroidism (i.e., increased thyrotropin (TSH)) were excluded. Younger participants (i.e., aged $<20$ years) were also excluded, yielding a final sample of 4846 (aged 20-97 years). All had routine medical examinations including: (i) measurements of height, weight, systolic blood pressure (SBP) and diastolic blood pressure (DBP); (ii) medical history, including therapy; (iii) blood sampling (see below); and (iv) carotid ultrasound (see below).

Each participant signed an informed consent form. All study methods were conducted according to the principles expressed in the Declaration of Helsinki and were approved by the governing Ethics Committee, Azienda Sanitaria Locale 4 (ASL4), protocol no. 2171/CE.

\subsection{Biochemical and Hormone Assays}

Venous blood samples were drawn between 7 and 8 a.m. after an overnight fast. Serum samples were stored at $-80^{\circ} \mathrm{C}$ until use. Plasma triglycerides and total cholesterol were determined by an enzymatic method (Abbott Laboratories ABA-200 ATC Biochromatic Analyzer, Irving, TX, USA). High density lipoprotein cholesterol (HDL) was determined by dextran sulphate-magnesium precipitation. Low density lipoprotein (LDL) concentrations were estimated by the Friedewald formula. Fasting plasma glucose concentration was measured by the glucose oxidase method (Beckman Instruments Inc., Fullerton, CA, USA).

TSH and FT4 were assessed with a two-site, solid-phase chemiluminescent immunometric assay, as described elsewhere [28]. Normal values are considered to be in the range TSH, $0.4-4.0 \mu \mathrm{IU} / \mathrm{mL} ; \mathrm{FT} 4,0.89-1.76 \mathrm{ng} / \mathrm{dL}$.

Overt hyperthyroidism was diagnosed in the presence of reduced TSH and FT4, displaying levels over the higher limit of the reference range. We defined subclinical hyperthyroidism as the presence of serum FT4 level in the normal reference range together 
with low serum TSH. Euthyroidism was defined as the presence of TSH concentration within the reference range.

\subsection{Arterial Structure and Function}

Carotid ultrasound was performed with a linear-array, 5- to 10-MHz transducer (Ultramark 9 HDI, Advanced Technology Laboratories, Inc., Seattle, WA, USA), as previously described. Briefly, the subject was placed in the supine position with his/her neck in extension and rolled contralaterally by about $45^{\circ}$. The right common carotid artery was examined at $1.5 \mathrm{~cm}$ proximal to the carotid bifurcation. Carotid parameters, $\beta$ stiffness, strain, wall-lumen ratio (W/L), carotid cross-sectional area (CSA), stress and flow, were calculated as previously reported [29].

\subsection{Definition of Cardiovascular Risk Factors}

Hypertension was defined as SBP $\geq 140 \mathrm{mmHg}$, and/or DBP $\geq 90 \mathrm{mmHg}$, and/or self-reported use of antihypertensive drugs. Pulse pressure (PP) was defined as SBP-DBP. Body mass index (BMI) was calculated as weight $(\mathrm{kg}) / \mathrm{height}^{2}\left(\mathrm{~m}^{2}\right)$. Diabetes mellitus was defined as self-reported diagnosis of diabetes and/or self-reported use of antidiabetic drugs or elevated fasting glycated haemoglobin or fasting glycaemia, according to the American Diabetes Association guidelines [30]. Dyslipidaemia was defined as self-reported use of lipid-lowering medications or the finding of LDL levels $\geq 140 \mathrm{mg} / \mathrm{dL}$. Smokers were defined as current consumers of at least one cigarette per day. We defined the term "cardiovascular event" as the documented history of myocardial infarction or stroke.

Heart rate was determined by electrocardiography, recorded before collecting ultrasound scan of the carotid artery.

\subsection{Statistical Analysis}

Since continuous variables were not distributed normally (Shapiro-Wilk test), nonparametric tests (Wilcoxon rank-sum test, Kruskal-Wallis test and Spearman's correlation) were used for the univariate analysis. Mann-Whitney U test was used to compare groups of thyroid function, considering euthyroid as a control. To assess the relationship between dependent variables (parameters of carotid structure) and thyroid hormones (TSH and FT4), we used a stepwise regression analysis including all traits significantly associated with dependent variables. Although associated, SBD and DBP were not further included in the analyses due to the presence of collinearity. The final model included age, sex, BMI, PP, previous CV events, presence of hypertension, heart rate and FT4. To test the interaction terms, heart rate-by-FT4 was entered in the multilevel model. Tests of significance were two-sided, and a $p<0.05$ was assumed as statistically significant in Stata 12 for Mac.

\section{Results}

Descriptive analyses are presented in Table 1, stratified by categories of thyroid function. Subjects with subclinical hyperthyroidism were older, had higher blood pressure values and levels of glycemia ( $p<0.001$ for all), and lower concentrations of triglycerides $(p<0.05)$ as compared to euthyroidism. In addition, participants with subclinical hyperthyroidism had higher BMI $(p<0.001)$, and HDL $(p<0.005)$ values in comparison to euthyroid individuals. Subjects with overt hyperthyroidism had a higher PP and DBP $(p<0.05)$ and heart rate $(p<0.001)$. Frequency of diabetes and hypertension was increased in subclinical hyperthyroidism. 
Table 1. Descriptive characteristics of the sample.

\begin{tabular}{|c|c|c|c|c|}
\hline & $\begin{array}{c}\text { Overt } \\
\text { Hyperthyroidism }\end{array}$ & $\begin{array}{c}\text { Subclinical } \\
\text { Hyperthyroidism }\end{array}$ & Euthyroidism & Total \\
\hline $\mathrm{n}$ & 24 & 136 & 4686 & 4846 \\
\hline Age, yrs & $44.8(31.3-64.4)$ & $57.7(45.8-67.3) *$ & $43.2(32.2-57.5)$ & $43.5(32.5-58.0)$ \\
\hline BMI, $\mathrm{Kg} / \mathrm{m}^{2}$ & $26.7(22.6-29.9)$ & $26.6(23.8-29.1)$ * & $25.1(22.3-28.2)$ & $25.2(22.3-28.3)$ \\
\hline Glycemia, mg/dL & $85(79-94)$ & $90(82-101) *$ & $86(79-94)$ & $86(79-94)$ \\
\hline Total cholesterol, mg/dL & $202(168-232)$ & $212(186-244)$ & $211(184-239)$ & $211(184-239)$ \\
\hline $\mathrm{LDL}, \mathrm{mg} / \mathrm{dL}$ & $119(102-142)$ & $130(111-155)$ & $128(105-151)$ & $128(106-151)$ \\
\hline $\mathrm{HDL}, \mathrm{mg} / \mathrm{dL}$ & $61(52-73)$ & $65(56-74)^{\#}$ & $63(54-73)$ & $63(54-73)$ \\
\hline Triglycerides, mg/dL & $68(51-96)$ & $63(48-88)^{\#}$ & $74(52-108)$ & $73(52-107)$ \\
\hline SBP & $125(112-140)$ & $130(119-145)$ * & $123(113-137)$ & $123(113-137)$ \\
\hline $\mathrm{DBP}$ & $70(67-80) \# \#$ & $80(73-86) *$ & $77(70-85)$ & $77(70-85)$ \\
\hline PP & $51(43-62) \# \#$ & $50(41-61)$ * & $47(40-55)$ & $47(40-55)$ \\
\hline Heart rate & $76(71-87)^{* *}$ & $67(60-76)$ & $66(59-74)$ & $66(59-74)$ \\
\hline $\mathrm{TSH}, \mathrm{mUI} / \mathrm{mL}$ & $0.11(0.01-0.04)^{* *}$ & $0.24(0.11-0.33)$ * & $1.56(1.04-2.17)$ & $1.52(1.00-2.15)$ \\
\hline $\mathrm{FT} 4, \mathrm{ng} / \mathrm{mL}$ & $2.04(1.90-2.35)^{* *}$ & $1.33(1.18-1.46)$ & $1.28(1.17-1.41)$ & $1.29(1.17-1.41)$ \\
\hline Female, n (\%) & $16(66.7 \%)$ & $85(62.5 \%)$ & $2580(55.1 \%)$ & $2681(55.3 \%)$ \\
\hline Smoker, n (\%) & $8(33.3 \%)$ & $16(11.8 \%)^{\#}$ & $986(21.4 \%)$ & $1010(20.8 \%)$ \\
\hline CV event, n (\%) & $0(0.0 \%)$ & $3(2.2 \%)$ & $71(1.5 \%)$ & $74(1.5 \%)$ \\
\hline Diabetes, n (\%) & $2(8.3 \%)$ & $15(11.0 \%)$ * & $211(4.5 \%)$ & $228(4.7 \%)$ \\
\hline Dyslipidemia, n (\%) & $2(8.3 \%)$ & $32(22.1 \%)$ & $971(20.7 \%)$ & $1005(20.7 \%)$ \\
\hline Hypertension, n (\%) & $8(33.3 \%)$ & $58(42.7 \%) *$ & $1396(29.8 \%)$ & $1462(30.2 \%)$ \\
\hline
\end{tabular}

BMI, body mass index; LDL, low density lipoprotein cholesterol; HDL, high density lipoprotein cholesterol; SBP, systolic blood pressure; DBP, diastolic blood pressure; PP, pulse pressure; TSH, thyrotropin, FT4, free thyroxine, CV, cardiovascular. * Subclinical hyperthyroidism vs. euthyroidism, $p<0.001$; \# Subclinical hyperthyroidism vs. euthyroidism, $p<0.05$; ${ }^{* *}$ Overt hyperthyroidism vs. euthyroidism, $p<0.001$; \#\# Overt hyperthyroidism vs. euthyroidism, $p<0.05$.

Table 2 shows cardiovascular parameters at the right common carotid level. Subjects with subclinical hyperthyroidism had a higher stiffness index, circumferential stress area (CSA), and circumferential stress and lower strain $(p<0.001$ for all). Subjects with overt hyperthyroidism had higher wall-lumen ratios as compared to euthyroid, although this was not statistically significant.

Table 2. Effect of thyroid status on common carotid structure.

\begin{tabular}{ccccc}
\hline & $\begin{array}{c}\text { Overt } \\
\text { Hyperthyroidism }\end{array}$ & $\begin{array}{c}\text { Subclinical } \\
\text { Hyperthyroidism }\end{array}$ & Euthyroidism & Total \\
\hline CCA stiffness & $6.87(4.78-9.10)$ & $6.88(5.54-8.96)^{*}$ & $5.78(4.58-7.66)$ & $5.81(4.60-7.70)$ \\
CCA strain, \% & $8.51(7.55-13.0)$ & $7.94(6.00-10.4)^{*}$ & $8.93(6.82-11.3)$ & $8.89(6.78-11.3)$ \\
CCA CSA & $21.5(18.8-24.6)$ & $22.0(18.6-27.4)^{*}$ & $19.6(16.9-23.7)$ & $19.6(17.0-23.8)$ \\
CCA W/L & $0.215(0.175-0.244)$ & $0.215(0.196-0.240)^{*}$ & $0.200(0.177-0.223)$ & $0.200(0.178-0.224)$ \\
CCA stress & $19.9(15.5-21.9)$ & $20.8(17.8-24.8){ }^{*}$ & $18.3(15.8-21.6)$ & $18.4(15.8-21.7)$ \\
\hline
\end{tabular}

CCA, common carotid artery; CSA, circumferential stress area; W/L, wall to lumen ratio. * Subclinical hyperthyroidism vs. euthyroidism, $p<0.001$.

Table 3 shows the effects of FT4 and heart rate on parameters of common carotid structure. FT4 showed a positive and significant association with the $\beta$ stiffness index $(\beta=0.026$, $p<0.05)$ and an inverse association with strain $(\beta=-0.025, p<0.05)$. After adding heart rate and the interaction term between FT4 and heart rate (FT4-by-heart rate) to the model, FT4 was still associated with $\beta$ stiffness index $(\beta=0.186, p=0.06)$, heart rate was positively associated with stiffness index $(\beta=0.389, p<0.001)$ and the interaction between the two $(\beta=0.271, p=0.007)$. 
Table 3. Predictors of parameters of common carotid structure.

\begin{tabular}{ccccccc}
\hline & & Beta Stiffness * & Strain * & W/L & CSA & Stress * \\
\hline Model a & & & & & & \\
FT4 & $\beta$ & 0.026 & -0.025 & 0.010 & 0.010 & 0.013 \\
& $p$ value & 0.041 & 0.048 & 0.472 & 0.319 & 0.303 \\
\hline Model b & & & & & \\
FT4 & $\beta$ & 0.186 & -0.109 & 0.060 & 0.018 & 0.072 \\
& $p$ value & 0.006 & 0.103 & 0.438 & 0.748 & 0.305 \\
Heart rate & $\beta$ & 0.389 & -0.342 & -0.001 & -0.143 & 0.031 \\
& $p$ value & $<0.001$ & $<0.001$ & 0.992 & 0.812 & 0.679 \\
FT4-by-heart rate & $\beta$ & 0.271 & 0.160 & -0.070 & -0.001 & 0.086 \\
& $p$ value & 0.007 & 0.113 & 0.550 & 0.913 & 0.415 \\
\hline
\end{tabular}

* Adjusted for age, sex, body mass index, pulse pressure, previous cardiovascular events.

TSH was not associated with any of the carotid parameters.

\section{Discussion}

We report a primary finding of the association between thyroid hormone and carotid parameters at the common carotid level, showing a positive association of FT4 with local arterial stiffening.

The role of thyroid hormone in the cardiovascular system has long been clear, with both hypothyroidism and hyperthyroidism associated with detrimental effects. Hypothyroidism leads to a worse lipid profile, with increased total cholesterol, LDL and triglyceride levels, while hyperthyroidism increases the risk of cardiac arrhythmias, heart failure, and ischemic stroke, especially in elderly patients. While these associations are clearly present in case of overt dysfunctions, there is no agreement about their effects in subclinical disorders [7,31].

The stiffening of arteries can be easily measured with carotid-femoral PWV, which is an independent risk factor for $\mathrm{CV}$ disease, all-cause mortality, and CV mortality. Some reports have found additional associations with mortality in type 2 diabetes [32] and end-stage renal disease [33]. However, the carotid-femoral PWV reflects the structural properties of the aorta, including elastic and muscular features. By contrast, the carotid is mostly elastic in nature, and its stiffness predicts the incident of stroke independently of other CV risk factors and aortic stiffness [34]. Thus, it is important to measure arterial stiffness at different sites along the non-uniform arterial tree.

Our analyses show that stiffness was increased in subjects with subclinical and overt hyperthyroidism, as shown in Table 2. However, the univariate analysis reported a nonprogressive increase along with increasing values of FT4, which was probably due to the higher age of the subjects with subclinical hyperthyroidism. Indeed-and indicated clearly by the multivariate analysis, even after adjusting for different cardiovascular variablesFT4 has a positive and direct association with stiffness. Clinical conditions characterized by increased concentrations of thyroid hormone, even if mild, can have a detrimental effect on the CV system. Indeed, subclinical hyperthyroidism has been reported as being associated with an increased risk of ischemic stroke in different studies, mainly due to a "trigger effect" on the onset of atrial fibrillation, though other studies failed to find such an association. Because carotid stiffening may lead to rupture of atherosclerotic carotid plaques [35], it can be speculated that an excess of thyroid hormone can increase the risk of stroke through two different mechanisms: by increasing the risk of atrial fibrillation and by increasing stiffness at the common carotid level. This hypothesis needs to be tested with specific studies, which are not feasible in this study. One can also suggest that atherosclerosis is more common in patients with subclinical hypothyroidism due to the more atherogenic lipid profile. However, it should be noted that some studies failed to report an increased frequency of atherosclerotic plaque in patients with subclinical hypothyroidism, as compared to euthyroid and subclinical hyperthyroidism patients [36]. Understanding the impact of thyroid disorders on atherosclerosis is further complicated by 
the findings of Volzke et al., who reported increased intima-media thickness in patients with subclinical hyperthyroidism [37].

The relationship between thyroid hormone and carotid stiffness is, thus, intricate and studies in the literature are inconclusive. Tatar et al. reported an inverse association between carotid stiffness and free triiodothyronine in a sample of 137 patients with endstage renal disease on hemodialysis [38]. The same group reported similar results in euthyroid patients on peritoneal dialysis [39]. Another study found increased stiffness at the common carotid level in 46 hypothyroid individuals compared to healthy controls [40]. Treatment with levo-thyroxine reversed the arterial stiffness, apart from the thickening of the artery wall [41]. On the other hand, consistent with our results, stiffness at the common carotid level has been reported to be increased in hyperthyroid patients with Graves' disease [42].

The interpretation of these divergent results is not clear, but it should be taken into account that the samples in these studies were small, and statistical analyses were not always adjusted for cardiovascular risk factors. By contrast, our multivariate analysis, adjusted for age, sex, BMI, PP, hypertension, and CV events, showed that FT4 had a direct effect on carotid $\beta$ stiffness. An additional finding of our study is the interaction between FT4 and heart rate. An elevated resting heart rate is associated with CV events, CV death and all-cause mortality [43]. In addition, it has been reported that a higher resting heart rate itself is associated with increased arterial stiffness, with a stronger association observed for the carotid artery compared with the central artery [44]. Thus, a likely explanation of our findings is that FT4 increased carotid stiffness by increasing heart rate.

Accordingly, thyroid hormones decrease systemic vascular resistance by vasodilation of the peripheral circulation [45], possibly as a direct action on vascular smooth muscle cells or through stimulation of the levels of vasodilatory endothelium-derived substances such as nitric oxide. Thus, a higher FT4 level could result in higher levels of triiodothyronine, thus affecting peripheral vasodilation and reflex cardiac effects such as increases in stroke volume and heart rate. A direct thyroid effect enhancing sinoatrial node activity could also contribute to the increase in heart rate [46]. However, other possible mechanisms cannot be excluded at present. For example, increased total artery stiffness may be a dynamic adaptation to the hypermetabolic state, promoting blood distribution into the peripheral vascular system.

In summary, we found an association between FT4 and arterial stiffness at the common carotid level. In line with the findings of this study, we previously showed that FT4 has a direct positive association with carotid-femoral PWV [25]. This suggests that higher FT4 levels have a detrimental effect on both mixed elastic and muscular arteries, as well as on the more prevalent elastic arteries such as the carotid artery. The effect of FT4 is likely attributable to the effect of FT4 on heart rate.

Author Contributions: A.P.D., wrote the manuscript. A.S., E.G.L., D.S., and F.C. edited the manuscript. E.F., and V.O. collected the data and edited the manuscript. All authors have read and agreed to the published version of the manuscript.

Funding: This work was supported in part by Contract NO1-AG-1-2109 from the NIH, National Institute on Aging.

Institutional Review Board Statement: Azienda Sanitaria Locale n ${ }^{\circ} 4$ (ASL4), protocol no. 2171/CE.

Informed Consent Statement: Informed consent was obtained from all subjects involved in the study.

Data Availability Statement: The data presented in this study are available on request from the corresponding author.

Conflicts of Interest: The authors declare no conflict of interest. 


\section{References}

1. Biondi, B. Mechanisms in endocrinology: Heart failure and thyroid dysfunction. Eur. J. Endocrinol. 2012, 167, 609-618. [CrossRef] [PubMed]

2. Delitala, A.P.; Steri, M.; Pilia, M.G.; Dei, M.; Lai, S.; Delitala, G.; Schlessinger, D.; Cucca, F. Menopause modulates the association between thyrotropin levels and lipid parameters: The SardiNIA study. Maturitas 2016, 92, 30-34. [CrossRef] [PubMed]

3. Meisinger, C.; Ittermann, T.; Tiller, D.; Agger, C.; Nauck, M.; Schipf, S.; Wallaschofski, H.; Jorgensen, T.; Linneberg, A.; Thiery, J.; et al. Sex-specific associations between thyrotropin and serum lipid profiles. Thyroid 2014, 24, 424-432. [CrossRef] [PubMed]

4. Biondi, B.; Cappola, A.R.; Cooper, D.S. Subclinical Hypothyroidism: A Review. JAMA 2019, 322, 153-160. [CrossRef] [PubMed]

5. Biondi, B.; Wartofsky, L. Treatment with thyroid hormone. Endocr. Rev. 2014, 35, 433-512. [CrossRef]

6. Skelton, C.L. The heart and hyperthyroidism. N. Engl. J. Med. 1982, 307, 1206-1208. [CrossRef]

7. Delitala, A.P. Subclinical Hyperthyroidism and the Cardiovascular Disease. Horm. Metab. Res. 2017, 49, 723-731. [CrossRef]

8. Scuteri, A.; Rovella, V.; Alunni Fegatelli, D.; Tesauro, M.; Gabriele, M.; Di Daniele, N. An operational definition of SHATS (Systemic Hemodynamic Atherosclerotic Syndrome): Role of arterial stiffness and blood pressure variability in elderly hypertensive subjects. Int. J. Cardiol. 2018, 263, 132-137. [CrossRef]

9. Pettersson-Pablo, P.; Cao, Y.; Breimer, L.H.; Nilsson, T.K.; Hurtig-Wennlof, A. Pulse wave velocity, augmentation index, and carotid intima-media thickness are each associated with different inflammatory protein signatures in young healthy adults: The lifestyle, biomarkers and atherosclerosis study. Atherosclerosis 2020, 313, 150-155. [CrossRef]

10. Ben-Shlomo, Y.; Spears, M.; Boustred, C.; May, M.; Anderson, S.G.; Benjamin, E.J.; Boutouyrie, P.; Cameron, J.; Chen, C.H.; Cruickshank, J.K.; et al. Aortic pulse wave velocity improves cardiovascular event prediction: An individual participant meta-analysis of prospective observational data from 17,635 subjects. J. Am. Coll. Cardiol. 2014, 63, 636-646. [CrossRef]

11. Gomez-Marcos, M.A.; Gonzalez-Elena, L.J.; Recio-Rodriguez, J.I.; Rodriguez-Sanchez, E.; Magallon-Botaya, R.; Munoz-Moreno, M.F.; Patino-Alonso, M.C.; Garcia-Ortiz, L. Cardiovascular risk assessment in hypertensive patients with tests recommended by the European Guidelines on Hypertension. Eur. J. Prev. Cardiol. 2012, 19, 515-522. [CrossRef] [PubMed]

12. Milan, A.; Zocaro, G.; Leone, D.; Tosello, F.; Buraioli, I.; Schiavone, D.; Veglio, F. Current assessment of pulse wave velocity: Comprehensive review of validation studies. J. Hypertens. 2019, 37, 1547-1557. [CrossRef] [PubMed]

13. Scuteri, A.; Franco, O.H.; Majiid, A.; Jolita, B.; Sergey, B.; Cheng, H.M.; Chen, C.H.; Choi, S.W.; Francesco, C.; De Buyzere, M.L.; et al. The relationship between the metabolic syndrome and arterial wall thickness: A mosaic still to be interpreted. Atherosclerosis 2016, 255, 11-16. [CrossRef] [PubMed]

14. Scuteri, A.; Chen, C.H.; Yin, F.C.; Chih-Tai, T.; Spurgeon, H.A.; Lakatta, E.G. Functional correlates of central arterial geometric phenotypes. Hypertension 2001, 38, 1471-1475. [CrossRef] [PubMed]

15. Jimenez-Balado, J.; Maisterra, O.; Delgado, P. Non-invasive markers of vascular disease: An opportunity for early diagnosis of cognitive impairment. Atherosclerosis 2020, 312, 101-103. [CrossRef] [PubMed]

16. Yang, E.Y.; Chambless, L.; Sharrett, A.R.; Virani, S.S.; Liu, X.; Tang, Z.; Boerwinkle, E.; Ballantyne, C.M.; Nambi, V. Carotid arterial wall characteristics are associated with incident ischemic stroke but not coronary heart disease in the Atherosclerosis Risk in Communities (ARIC) study. Stroke 2012, 43, 103-108. [CrossRef]

17. van Sloten, T.T.; Schram, M.T.; van den Hurk, K.; Dekker, J.M.; Nijpels, G.; Henry, R.M.; Stehouwer, C.D. Local stiffness of the carotid and femoral artery is associated with incident cardiovascular events and all-cause mortality: The Hoorn study. J. Am. Coll. Cardiol. 2014, 63, 1739-1747. [CrossRef]

18. Zanoli, L.; Empana, J.P.; Perier, M.C.; Alivon, M.; Ketthab, H.; Castellino, P.; Laude, D.; Thomas, F.; Pannier, B.; Laurent, S.; et al. Increased carotid stiffness and remodelling at early stages of chronic kidney disease. J. Hypertens. 2019, 37, 1176-1182. [CrossRef]

19. Lacolley, P.; Regnault, V.; Segers, P.; Laurent, S. Vascular Smooth Muscle Cells and Arterial Stiffening: Relevance in Development, Aging, and Disease. Physiol. Rev. 2017, 97, 1555-1617. [CrossRef]

20. Scuteri, A.; Stuehlinger, M.C.; Cooke, J.P.; Wright, J.G.; Lakatta, E.G.; Anderson, D.E.; Fleg, J.L. Nitric oxide inhibition as a mechanism for blood pressure increase during salt loading in normotensive postmenopausal women. J. Hypertens. 2003, 21, 1339-1346. [CrossRef]

21. Farasat, S.M.; Morrell, C.H.; Scuteri, A.; Ting, C.T.; Yin, F.C.; Spurgeon, H.A.; Chen, C.H.; Lakatta, E.G.; Najjar, S.S. Pulse pressure is inversely related to aortic root diameter implications for the pathogenesis of systolic hypertension. Hypertension 2008, 51, 196-202. [CrossRef] [PubMed]

22. Boutouyrie, P.; Bussy, C.; Lacolley, P.; Girerd, X.; Laloux, B.; Laurent, S. Association between local pulse pressure, mean blood pressure, and large-artery remodeling. Circulation 1999, 100, 1387-1393. [CrossRef] [PubMed]

23. Dagre, A.G.; Lekakis, J.P.; Papaioannou, T.G.; Papamichael, C.M.; Koutras, D.A.; Stamatelopoulos, S.F.; Alevizaki, M. Arterial stiffness is increased in subjects with hypothyroidism. Int. J. Cardiol. 2005, 103, 1-6. [CrossRef] [PubMed]

24. del Busto-Mesa, A.; Cabrera-Rego, J.O.; Carrero-Fernandez, L.; Hernandez-Roca, C.V.; Gonzalez-Valdes, J.L.; de la Rosa-Pazos, J.E. Changes in arterial stiffness, carotid intima-media thickness, and epicardial fat after L-thyroxine replacement therapy in hypothyroidism. Endocrinol. Nutr. 2015, 62, 270-276. [CrossRef]

25. Delitala, A.P.; Orru, M.; Filigheddu, F.; Pilia, M.G.; Delitala, G.; Ganau, A.; Saba, P.S.; Decandia, F.; Scuteri, A.; Marongiu, M.; et al . Serum free thyroxine levels are positively associated with arterial stiffness in the SardiNIA study. Clin. Endocrinol. 2015, 82, 592-597. [CrossRef] 
26. Delitala, A.P.; Steri, M.; Fiorillo, E.; Marongiu, M.; Lakatta, E.G.; Schlessinger, D.; Cucca, F. Adipocytokine correlations with thyroid function and autoimmunity in euthyroid sardinians. Cytokine 2018, 111, 189-193. [CrossRef]

27. Delitala, A.P.; Scuteri, A.; Fiorillo, E.; Lakatta, E.G.; Schlessinger, D.; Cucca, F. Role of Adipokines in the Association between Thyroid Hormone and Components of the Metabolic Syndrome. J. Clin. Med. 2019, 8, 764. [CrossRef]

28. Delitala, A.P.; Terracciano, A.; Fiorillo, E.; Orru, V.; Schlessinger, D.; Cucca, F. Depressive symptoms, thyroid hormone and autoimmunity in a population-based cohort from Sardinia. J. Affect. Disord. 2016, 191, 82-87. [CrossRef]

29. Scuteri, A.; Najjar, S.S.; Orru, M.; Usala, G.; Piras, M.G.; Ferrucci, L.; Cao, A.; Schlessinger, D.; Uda, M.; Lakatta, E.G. The central arterial burden of the metabolic syndrome is similar in men and women: The SardiNIA Study. Eur. Heart J. 2010, 31, 602-613. [CrossRef]

30. American Diabetes, A. 2. Classification and Diagnosis of Diabetes: Standards of Medical Care in Diabetes-2020. Diabetes Care 2020, 43, S14-S31. [CrossRef]

31. Delitala, A.P.; Scuteri, A.; Maioli, M.; Mangatia, P.; Vilardi, L.; Erre, G.L. Subclinical hypothyroidism and cardiovascular risk factors. Minerva Med. 2019, 110, 530-545. [CrossRef] [PubMed]

32. Cruickshank, K.; Riste, L.; Anderson, S.G.; Wright, J.S.; Dunn, G.; Gosling, R.G. Aortic pulse-wave velocity and its relationship to mortality in diabetes and glucose intolerance: An integrated index of vascular function? Circulation 2002, 106, 2085-2090. [CrossRef] [PubMed]

33. Blacher, J.; Guerin, A.P.; Pannier, B.; Marchais, S.J.; Safar, M.E.; London, G.M. Impact of aortic stiffness on survival in end-stage renal disease. Circulation 1999, 99, 2434-2439. [CrossRef] [PubMed]

34. van Sloten, T.T.; Sedaghat, S.; Laurent, S.; London, G.M.; Pannier, B.; Ikram, M.A.; Kavousi, M.; Mattace-Raso, F.; Franco, O.H.; Boutouyrie, P.; et al. Carotid stiffness is associated with incident stroke: A systematic review and individual participant data meta-analysis. J. Am. Coll. Cardiol. 2015, 66, 2116-2125. [CrossRef] [PubMed]

35. Selwaness, M.; van den Bouwhuijsen, Q.; Mattace-Raso, F.U.; Verwoert, G.C.; Hofman, A.; Franco, O.H.; Witteman, J.C.; van der Lugt, A.; Vernooij, M.W.; Wentzel, J.J. Arterial stiffness is associated with carotid intraplaque hemorrhage in the general population: The Rotterdam study. Arterioscler. Thromb. Vasc. Biol. 2014, 34, 927-932. [CrossRef] [PubMed]

36. Delitala, A.P.; Filigheddu, F.; Orru, M.; AlGhatrif, M.; Steri, M.; Pilia, M.G.; Scuteri, A.; Lobina, M.; Piras, M.G.; Delitala, G.; et al. No evidence of association between subclinical thyroid disorders and common carotid intima medial thickness or atherosclerotic plaque. Nutr. Metab. Cardiovasc. Dis. 2015, 25, 1104-1110. [CrossRef] [PubMed]

37. Volzke, H.; Robinson, D.M.; Schminke, U.; Ludemann, J.; Rettig, R.; Felix, S.B.; Kessler, C.; John, U.; Meng, W. Thyroid function and carotid wall thickness. J. Clin. Endocrinol. Metab. 2004, 89, 2145-2149. [CrossRef]

38. Tatar, E.; Kircelli, F.; Asci, G.; Carrero, J.J.; Gungor, O.; Demirci, M.S.; Ozbek, S.S.; Ceylan, N.; Ozkahya, M.; Toz, H.; et al. Associations of triiodothyronine levels with carotid atherosclerosis and arterial stiffness in hemodialysis patients. Clin. J. Am. Soc. Nephrol. 2011, 6, 2240-2246. [CrossRef]

39. Tatar, E.; Sezis Demirci, M.; Kircelli, F.; Gungor, O.; Yaprak, M.; Asci, G.; Basci, A.; Ozkahya, M.; Ok, E. The association between thyroid hormones and arterial stiffness in peritoneal dialysis patients. Int. Urol. Nephrol. 2012, 44, 601-606. [CrossRef] [PubMed]

40. Nagasaki, T.; Inaba, M.; Shirakawa, K.; Hiura, Y.; Tahara, H.; Kumeda, Y.; Ishikawa, T.; Ishimura, E.; Nishizawa, Y. Increased levels of C-reactive protein in hypothyroid patients and its correlation with arterial stiffness in the common carotid artery. Biomed. Pharmacother. 2007, 61, 167-172. [CrossRef]

41. Nagasaki, T.; Inaba, M.; Kumeda, Y.; Ueda, M.; Hiura, Y.; Tahara, H.; Ishimura, E.; Onoda, N.; Ishikawa, T.; Nishizawa, Y. Decrease of arterial stiffness at common carotid artery in hypothyroid patients by normalization of thyroid function. Biomed. Pharmacother. 2005, 59, 8-14. [CrossRef] [PubMed]

42. Czarkowski, M.; Hilgertner, L.; Powalowski, T.; Radomski, D. The stiffness of the common carotid artery in patients with Graves' disease. Int. Angiol. 2002, 21, 152-157. [PubMed]

43. Fox, K.; Borer, J.S.; Camm, A.J.; Danchin, N.; Ferrari, R.; Lopez Sendon, J.L.; Steg, P.G.; Tardif, J.C.; Tavazzi, L.; Tendera, M.; et al. Resting heart rate in cardiovascular disease. J. Am. Coll. Cardiol. 2007, 50, 823-830. [CrossRef] [PubMed]

44. Whelton, S.P.; Blankstein, R.; Al-Mallah, M.H.; Lima, J.A.; Bluemke, D.A.; Hundley, W.G.; Polak, J.F.; Blumenthal, R.S.; Nasir, K.; Blaha, M.J. Association of resting heart rate with carotid and aortic arterial stiffness: Multi-ethnic study of atherosclerosis. Hypertension 2013, 62, 477-484. [CrossRef] [PubMed]

45. Ojamaa, K.; Klemperer, J.D.; Klein, I. Acute effects of thyroid hormone on vascular smooth muscle. Thyroid 1996, 6, 505-512. [CrossRef]

46. Valcavi, R.; Menozzi, C.; Roti, E.; Zini, M.; Lolli, G.; Roti, S.; Guiducci, U.; Portioli, I. Sinus node function in hyperthyroid patients. J. Clin. Endocrinol. Metab. 1992, 75, 239-242. 